\title{
EDITORIAL
}

\section{ENFERMERAS TIPO TEST}

\author{
Alfonso M. García Hernández \\ Universidad de La Laguna
}

Hace años, y no pocos, que tomé partido por los mapas conceptuales. Como las personas, los mapas, siempre toman partido. Nos dicen dónde y de qué lado están. Hacen visibles algunas cosas y ocultan otras de modo que cubren y descubren, forman y deforman. Lo que no son es neutrales como muchos creen, al igual que lo es la educación y la pedagogía sobre la que a continuación voy a reflexionar a lo largo de la presente editorial en un sentido general, como tarea educativa emprendida en las aulas y de modo particular en la de las graduadas en enfermería.

Empleo la analogía para los educadores de enfermeras, de modo esquemático, como si se trataran de cartógrafos, quizá porque los límites y las fronteras nos ayudan a definir el orden y las relaciones entre las facultades, funciones y principios en sus diversas obras y porque al igual que el territorio no se agota en el mapa, el pensamiento no lo hace en el esquema (Sánchez y Alegre, 2019: 106). La narración nos proporciona una secuencia a modo de conexión, significado y perspectiva del otro ¿cómo conseguirlo con preguntas con respuesta tipo test?

La ciencia de la educación plenamente desarrollada nos garantizaría que los buenos educadores no sean una excepción. Lo cual requiere pensar la pedagogía desde los años veinte del presente siglo, que nos lleve a cuestionar el concepto de aprendizaje, de enseñanza reglada, de adquisición de normas e inmersión del individuo en una sociedad que cada vez más le percibe como obligado a trazarse un camino exitoso en su territorio, alejado de competencias colectivas y cercano al individualismo feroz, en un camino plagado de tecnología que absorbe al ser humano convirtiéndolo en ocasiones en un mero cuerpo.

No soy ajeno, en estos tiempo que vivimos que sigue siendo cierta la sentencia dictada por Platón hace casi dos mil años en el "Teeteto" donde nos refiere que "la sabiduría y la verdadera 
virtud no son otra cosa que el conocimiento de la justicia, y su desconocimiento es ignorancia y maldad manifiesta" de modo que se concibe la pedagogía como un territorio que marca, orienta y da claves para caminar profesionalmente por él.

Formar futuras enfermeras también requiere analizar lo que habría que hacer con la experiencia enfermera, una actividad de ajuste o una tarea reflexiva en la que incluso deberíamos definir a qué experiencia no estamos refiriendo. El arte de realizar las preguntas adecuadas y de establecer estrategias óptimas de comunicación, tan útiles en la práctica enfermera y en la clínica como vía para establecer una relación personalizada con el paciente, su familia y la comunidad me llevan a preguntarme sobre el papel que desempeña en esa mochila comunicativa la formación y o evaluación mediante estrategias "tipo test" y si estas están en el manual práctico de las técnicas comunicativas más allá de las respuestas directivas cercanas a la solución inmediata.

Debemos pues delimitar claramente nuestro mapa para el recorrido educativo de las futuras enfermeras, que incorpore cuidado, disciplina, ética, instrucción, con sus periodos cronológicos y analíticos, centrado en el cuidado y en la libertad que aúna formación en todas sus vertientes: valores, aspectos éticos y capacidades, además de aprender a pensar como camino para comprender la humanidad, una disciplina que no se muestre ajena a los peligros que debe salvaguardar como son la excesiva burocratización, llevada al extremo que se vive en ocasiones como intromisión en la libertad de cátedra del docente que se constriñe frente a un excesivo formalismo de su tarea, al ser entendida como ciencia reglada que asume como su impulso interno y modelo triunfante la misma.

Los conocimientos deben estar al servicio de los cuidados. La ciencia basada en los datos está ineludiblemente encaminada y enmarcada en la "ética del cuidado" y ambas cuestiones deben ir de la mano, consolidarse como valores. Aprender a investigar para aprender a cuidar, aunando conocimientos, valores y actitudes.

Nuestra experiencia clínica, de encuentro con el otro, de comprensión, se basa en gran medida en el conocimiento que nos proporcionan las biografías o historias de muchas personas con las que hemos compartido durante años. Nos acercan y posicionan frente a los otros, mediado por su narración que nos permite dar valor a la importancia y cantidad de factores que intervienen en su situación clínica y nos ayudan a no per- 
der una visión global de él o ella, a escucharle activamente, a atenderlo, a reflexionar e imaginar que el camino compartido con pacientes y familias sea en sí mismo terapéutico pues conecta ambos mundos, dispersa la soledad y aviva el interés y la toma de decisiones compartidas.

Como enfermera miles de preguntas se acumulan a lo largo de nuestra vida y son distintos los caminos que buscan dar respuesta a ellas. Muchas parten del sentido común, del arte, de la filosofía, de la deliberación sobre la narración, del método científico y de un largo etcétera. Todas ellas, buscan resolver un problema concreto aunque no todas ofrecen la misma garantía de acierto. En este sentido, la investigación académica en enfermería, se presenta no pocas veces marcada por la obligación, el dinero o la necesidad en lugar de por el placer y el disfrute del saber que para la enfermera supone el disfrute de cuidar a los otros, de amar lo que hacemos e ir progresando paulatinamente en nuestra afirmaciones científicas con más precisión.

La vida y el camino siguen, mientras, distintas cuestiones me siguen rondando cuando compañeras y compañeros docentes siguen usando preferentemente como método evaluativo los exámenes tipo test, y mi pregunta central sigue siendo ¿Cómo compartir y enfrentar las miradas del otro, una condición mínima para la intersubjetividad, en una disciplina en la que uno de sus fundamentos es atender a la mirada perdida de los otros?

\section{BiBLIOGRAFÍA}

Bayés, R. (2012). Aprender a investigar, aprender a cuidar. Una guía para estudiantes y profesionales de la salud. Barcelona. Plataforma editorial.

Platón (2014). Teeteto. Madrid. Gredos.

Sánchez, N., Alegre, L. (Coord.) (2019). Territorios por pensar. Un mapa conceptual del siglo XXI. Madrid. Siglo XXI de España Editores. 